\title{
LIETUVOS GYDYTOJŲ ODONTOLOGŲ IR GYDYTOJŲ ODONTOLOGŲ SPECIALISTŲ DARBO PRODUKTYVUMAS
}

\author{
Vilija Berlin, Alina Pūrienè, Monika Mackevičiūtè \\ Vilniaus universiteto Medicinos fakulteto Odontologijos institutas
}

Raktažodžiai: odontologų darbo produktyvumas, produktyvumą sąlygojantys veiksniai.

\begin{abstract}
Santrauka
Atsirandant priemonèms, palengvinančioms gydytojų odontologų ir gydytojų odontologų specialistų darbą, bei didejjant odontologų pasiūlai Lietuvoje, svarbu išsiaiškinti odontologu darbo produktyvumą ir palyginti ji su kitomis šalimis. Šie duomenys gali būti naudingi asmenims, planuojantiems gydytojų odontologų ir gydytojų odontologų specialistų poreikį Lietuvoje, klinikų administracijos darbuotojams, reguliuojantiems odontologų darbo produktyvumą.

Iš viso tyrime dalyvavo 2008 gydytojai (atsakomumo dažnis $67,6 \%$ ). Nustatyta, kad vidutiniškai per 6 valandų darbo dieną gydytojas odontologas ir gydytojas odontologas specialistas priima 8 pacientus. Daugiausia pacientų per dieną priima gydytojas ortodontas, mažiausiai - gydytojas endodontologas. Darbo produktyvumą statistiškai reikšmingai padidina padejejjas $(p=0,02)$. Gydytojai, kurie dirba didmiestyje, priima mažiau pacientu $(7,7 \pm 3,6)$ nei tie, kurie dirba kituose miestuose $(9 \pm 3,1)(p=0,04)$. Valstybineje istaigoje dirbantys odontologai priima $10,3 \pm 3,5$ pacientus, o privačioje $-7,6 \pm 3,3(\mathrm{p}<0,05)$. Nustatyta, kad darbo produktyvumui ịtakos turi darbo pobūdis. Samdomi gydytojai odontologai per dieną priima statistiškai daugiau pacientų $(\mathrm{p}=0,011)$ negu tie, kurie yra kliniku vadovai arba nuomojasi darbo vietą. Išvados: bendrosios praktikos gydytojai odontologai ir gydytojai odontologai specialistai priima toki patį pacientų skaičių. İtakos darbo našumui turi darboviete, padèjèjas, darbo pobūdis.
\end{abstract}

\section{İžanga}

Darbo produktyvumas (kitaip - darbo efektyvumas) apskaičiuojamas pagal paslaugų kieki per laiko vienetą. Tai yra vienas iš pagrindinių rodiklių gydytojų odontolo- gų ir gydytojų odontologų specialistų pajėgumui vertinti. Jis priklauso nuo įvairių veiksnių, kaip pavyzdžiui, darbo jègos, sąnaudų, gydytojo patirties, darbovietès. 2014 metų Europos Sajungos statistiniais duomenimis, Lietuva yra penktoje vietoje pagal odontologų skaičių, tenkantị 100000 gyventojų (1). Per 2009-2014 metų laikotarpi odontologų skaičius padidèjo trečdaliu. Buvo užfiksuotas didžiausias praktikuojančių gydytojų odontologų augimas visoje Europos Sajungoje (1). Nors Lietuva yra viena iš pirmaujančių Europos šalių pagal bendrą odontologų skaičių, odontologijos studijas pasirenkančių studentų skaičius nemažeja. Apskritai pasaulyje didèja gydytojų odontologų ir gydytojų odontologų specialistų pasiūla, o paklausa mažèja (2).

Kasdieniné odontologo praktika tampa lengvesnè dèl tobulesnių diagnostikos priemonių, naujų medžiagų, i̇ pagalbą vis dažniau pasitelkiamų kelių padèjējų (3). Ankstesnèse studijose, atliktose JAV, nustatyta, kad gydytojo odontologo padejjèjas akivaizdžiai padidina odontologo darbo produktyvumą (3).

Be to, pagal ekonominius paskaičiavimus JAV, yra įrodyta, kad siekiant užtikrinti produktyvų odontologinès klinikos darbą, gydytojas odontologas per darbo dieną turi priimti nuo 8 iki 12 pacientų (4).

Iki šiol gydytojų odontologų ir gydytojų odontologų specialistų produktyvumas bei tam ịtakos turintys veiksniai Lietuvoje nebuvo tirti. Šie duomenys gali būti naudingi asmenims, planuojantiems gydytojų odontologų ir gydytojų odontologų specialistu poreiki Lietuvoje, taip pat klinikų administracijos darbuotojams, reguliuojantiems odontologų darbo produktyvumą.

Tyrimo tikslas: ištirti, kiek pacientų per 6 valandų darbo dieną priima gydytojas odontologas ir gydytojas odontologas specialistas bei nustatyti tam įtakos turinčius veiksnius.

\section{Medžiaga ir metodai}

Gydytojų odontologų ir gydytojų odontologų specialistų anketinès apklausos tyrimas vykdytas 2012 metu gruodžio-2013 metų birželio mènesiais. 
Tyrimui buvo naudojama anketinė apklausa, sukurta remiantis ankščiau vykdytomis apklausomis Lietuvoje ir užsienyje. Anketą sudare 36 uždaro ir atviro tipo klausimai. Tyrimui vykdyti gautas Valstybinès duomenu apsaugos inspekcijos leidimas (2012 09 14, Nr. 2R-3247 (2.6.1) ir 201312 11, Nr. 2R-2149 (2.6- 1.). Jo pagrindu 2012 m. spalio 17 d. iš Lietuvos Respublikos odontologu rūmų licencijų registro duomenų bazès gauti visų Lietuvos gydytojų odontologų ir gydytojų odontologų specialistų, turinčių galiojančią odontologijos specialisto praktikos licenciją, duomenys (vardas, pavardè, profesinè kvalifikacija, amžius, gyvenamosios vietos adresas, elektroninio pašto adresas bei telefono numeris). Iš gautų duomenu buvo atmesti gydytojai veido ir žandikaulių chirurgai, emigravę ir nedirbantys pensinio amžiaus odontologai bei tie, kurių gauti kontaktiniai duomenys buvo netikslūs.

Siekiant surinkti kuo daugiau atsakytų anketų, gydytojai odontologai dalyvauti tyrime buvo kviečiami tris kartus. Pirmiausia anketa su tyrimo aprašymu ir apmokètu atgaliniu voku buvo siunčiama paprastu arba elektroniniu paštu, véliau, nesulaukus atsakymų, po 6 savaičių anketa išsiųsta pakartotinai, o dar po 6 savaičių skambinta telefonu.

Statistinè analizė atlikta naudojant SPSS (versija 20.0) programos metodus: aprašomoji statistika, chi kvadrato, ttestą.

\section{Rezultatai}

Iš viso tyrime dalyvavo 2008 gydytojai (atsakomumo dažnis 67,6\%), iš kurių bendrosios praktikos gydytojai odontologai sudare $81,9 \%$, o gydytojai odontologai specialistai $-18,1 \%$. Didžioji dalis respondentų buvo moterys $(\mathrm{N}=1704)$.

Du trečdaliai bendrosios praktikos gydytojų odontologų ir gydytojų odontologų specialistų dirba samdomą darbą

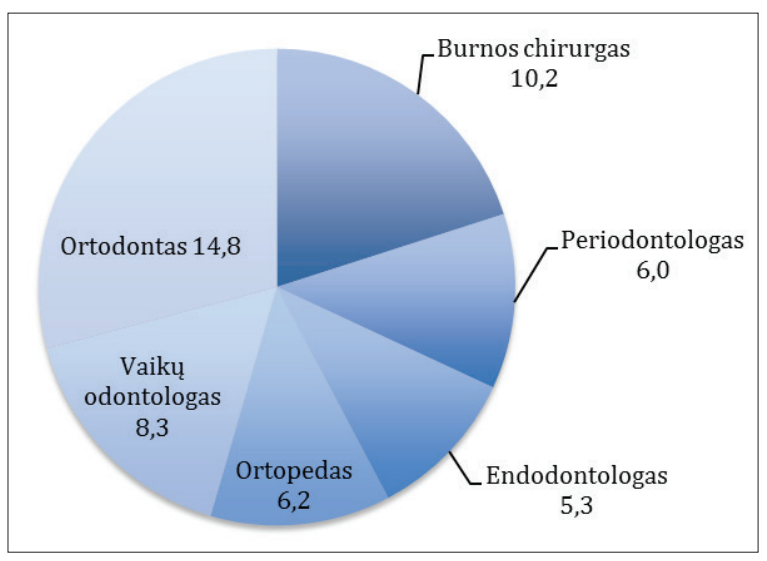

1 paveikslas. Vidutinis pacientų skaičius, kurị priima ịvairių odontologijos sričių specialistai per 6 valandų darbo dieną
$(79,9 \%)$. Nustatyta, kad darbo produktyvumui įtakos turi darbo pobūdis. Samdomi gydytojai odontologai per darbo dieną priima statistiškai daugiau pacientų $(\mathrm{p}=0,01)$ negu vadovai. Samdomų odontologų priimtų pacientų skaičiaus vidurkis $8,8 \pm 3,6$, vadovu $-7,6 \pm 3,1$.

Vidutiniškai per 6 valandų darbo dieną bendrosios praktikos gydytojas odontologas ir gydytojas odontologas specialistas priima 8 pacientus (gyd. odontologas $8,4 \pm 3,4$; gyd. odontologas specialistas- $8,5 \pm 5,2$ ).

Pagal specialybę daugiausia pacientų per darbo dieną priima gydytojai ortodontai, antroje vietoje - burnos chirurgai, mažiausiai pacientų priima gydytojai endodontologai (1 pav.).

$65,3 \%$ specialistu ir $35,1 \%$ bendrosios praktikos odontologu dirba visada su padejeju. Dvigubai daugiau bendrosios praktikos gydytojų dirba be padejejjo lyginant su specialistais (atitinkamai $24,2 \%$ ir $12,1 \%$ ).

Nustatytas statistinis ryšys tarp priimtu pacientų skaičiaus ir darbo su padejejju. Bendrosios praktikos gydytojas odontologas, kuris dirba visada vienas, priima mažiau pacientų $(7,9 \pm 3,3)$ nei tas, kuris kartais dirba vienas, o kartais su padejjèju $(8,9 \pm 3,7)(\mathrm{p}=0,02)$. Be to, tie bendrosios praktikos gydytojai odontologai, kurie visada dirba su padejjèju, priima statistiškai mažiau pacientų $(8,1 \pm 3,4)$ nei tie, kurie dirba kartais vieni, kartais su padejeju $(8,9 \pm 3,7)(\mathrm{p}=0,03)$. Nustatyta, kad gydytojų odontologų specialistų darbo našumas statistiškai reikšmingai padidejja, jei jiems visada asistuoja ( $\mathrm{p}=0,04)$ : su padejejeju priima vidutiniškai $8,4 \pm 4,9$ pacientus, be padèjèjo $-6,1 \pm 3,3$.

Gautas statistiškai patikimas ryšys tarp vietovės, kurioje bendrosios praktikos gydytojas odontologas dirba, ir priimtų pacientų skaičiaus. Gydytojai, kurie dirba didmiestyje, priima mažiau pacientų $(7,7 \pm 3,6)$ nei tie, kurie dirba kituose miestuose $(9,0 \pm 3,1)(\mathrm{p}=0,04)$ ( 2 pav.).

Gydytojai odontologai, dirbantys valstybiniame sektoriuje, per darbo dieną priima $10,3 \pm 3,5$ pacientus, o priva-

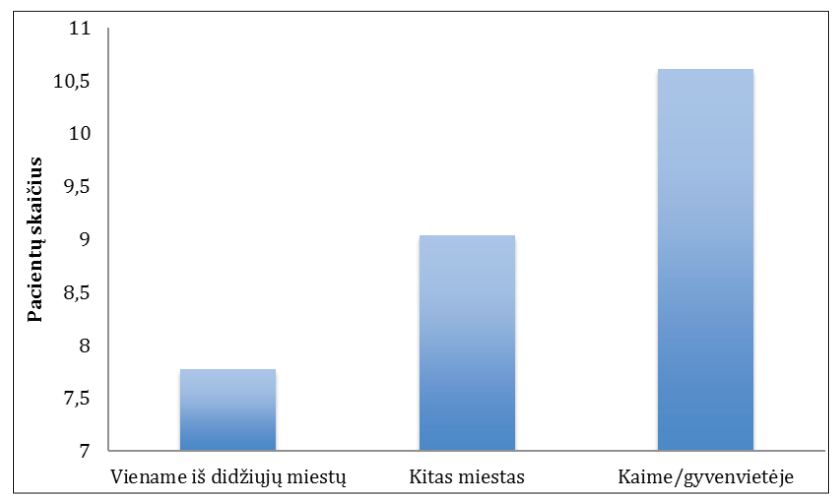

2 paveiklas. Darbo našumas pagal darbovietės vietą 
čiame $-7,6 \pm 3,3$ pacientus. Tai yra statistiškai reikšmingas skirtumas $(\mathrm{p}<0,05)$.

\section{Diskusija}

Šio tyrimo metu nustatyta, kad vidutinis pacientų skaičius, kuri priima bendosios praktikos gydytojas odontologas ir gydytojas odontologas specialistas, Lietuvoje yra apytiksliai lygus 8. Pagal JAV atliktą analizę nustatyta, kad kiekvienas odontologas, nepriklausomai, ar tai specialistas, ar bendrosios praktikos gydytojas, per 1 darbo dieną turi priimti nuo 8 iki 12 pacientų (4). Tokiu būdu bus užtikrintas produktyvus klinikos darbas. Vis dèlto, lyginant su kitomis šalimis, šis skaičius Lietuvoje yra mažesnis. Pavyzdžiui, JAV vidutiniškai gydytojas odontologas per darbo dieną priima 10 pacientų (3). Panašus priimtų pacientų skaičius nurodomas ir Jungtinėje Karalysteje (1). Padidinus odontologų produktyvumą būtų galima sumažinti odontologinių paslaugų ịkainius, praplèsti odontologinių paslaugų spektrą. Tokiu būdu būtų padidintas odontologinių paslaugų prieinamumas gyventojams, kas savo ruožtu padètų spręsti didelio odontologų skaičiaus problemą šalyje.

Odontologų darbo našumui ịtakos turi darbovietès vieta. Tyrimo metu nustatyta, kad mažiau pacientu priima odontologai, dirbantys didžiuosiuose Lietuvos miestuose. Tai galètų būti dèl to, kad gydytojų odontologų skaičius skirtingose vietovėse yra neproporcingas, todèl reikètu paskirstyti šį skaičių.

Be to, Lietuvoje beveik 17\% daugiau pacientų priima samdomi gydytojai, kai JAV 25\% daugiau pacientų priima klinikos vadovai (3).

Kaip ir kitose studijose $(3,5)$, šio tyrimo rezultatai parodè, kad gydytojų odontologų ir gydytojų odontologu specialistų darbo produktyvumas padidèja, kai yra dirbama kartu su padejjejju. Vis dèlto, tik trečdalis Lietuvos bendrosios praktikos gydytojų odontologų nurode, kad dirba su asistentu. Be to, tyrimo metu nustatyta, kad tie gydytojai, kurie dirba ir su padejejeju ir be jo, priima daugiau pacientu nei tie, kurie visada dirba su padejjeju. Tam įtakos galejjo turèti tai, kad valstybinèse įstaigose dirbantys gydytojai, kurie priima gerokai daugiau pacientų nei privačiose, neretai dirba be pastovaus padejejejo.

Apibendrinant, šiame tyrime gydytojų odontologų ir gydytojų odontologų specialistų darbo produktyvumas vertintas pagal priimtų pacientų skaičių. Vis dèlto, skaičiuojant darbo produktyvumą nebuvo atsižvelgta ị darbų sudètingumą, ekonominius rodiklius, kas ankstesniuose tyrimuose buvo įrodyta kaip priemonès, didinačios darbo produktyvumą (6). Be to, šioje studijoje nebuvo apibrèžtos padejjejo pareigybès, todèl ateityje reikia detalesnių tyrimų Lietuvos gydytojų odontologų ir gydytojų odontologų spe- cialistų darbo produktyvumui vertinti.

\section{Išvados}

1. Gydytojai odontologai ir gydytojai odontologai specialistai per 6 valandų darbo dieną priima 8 pacientus.

2. Daugiausiai pacientų per dieną priima gydytojai ortodontai.

3. Valstybineje ịstaigoje gydytojai odontologai priima didesni skaičiu pacientų.

4. Gydytojai odontologai ir gydytojai odontologai specialistai, dirbantys didžiuosiuose miestuose, priima mažiau pacientu.

5. Odontologo darbo produktyvumui svarbus padejeje vaidmuo.

\section{Literatūra}

1. British Dental Association. The State of General Dental Practice in 2013, 2013.

2. Beazoglou T, Heffley D, Brown LJ, Bailit H. The importance of productivity in estimating need for dentists. J Am Dent Assoc 2002 Oct;133(10):1399-404.

https://doi.org/10.14219/jada.archive.2002.0056

3. Conrad DA, Shuk-Yin LR, Northwest MP, Huebner EC. Estimating determinants of dentist productivity: new evidence. J Public Health Dent 2010 Fall. https://doi.org/10.1111/j.1752-7325.2010.00180.x

4. Schumann TC. 10 daily practice statistics every dentist should review, 2013.

5. Cottam W. Oral health workforce. 2011 National Primary Oral Health Conference.

6. Pourat N. Differences in characteristics of California dentists who employ dental hygienists and those who do not. J Am Dent Assoc 2009 Aug;140(8):1027-35.

https://doi.org/10.14219/jada.archive.2009.0315

\section{THE PRODUCTIVITY OF GENERAL DENTISTS AND DENTAL SPECIALISTS IN LITHUANIA}

\section{Berlin, A. Pūrienė, M. Mackevičiūtè}

Key words: productivity of dentists, determinants of dentist productivity.

Summary

In order to improve the performance and efficiency levels of their dental clinics, employers need to start focusing on their dentists' productivity and effectiveness at work. There are numerous factors influencing dentists' productivity: the workforce, input prices, dentists' experience. Up until now, there has been no research done on measuring the productivity levels of general dentists and dental specialists in Lithuania. This research would be useful not only for individuals, who control the supply of general dentists and dental specialists, but also private or public employers of dental clinics.

Objective. To analyze the factors that influence the numbers of 


\section{6}

patients a general dentist and a dental specialist can accept during a 6-hour working day. Materials and methods. A study was carried out among 2008 general dentists and dental specialists in Lithuania during the period $12 / 2012$ and $06 / 2013$. A structured questionnaire was used to identify the productivity of general dentists' and dental specialists' and to determine the influencing factors. Statistical analysis was performed using the SPSS software (version 20.0). Results. The average number of patients during a 6-hour working day was roughly the same between the two examined groups: general dentists took on average $8,4 \pm 3,4$, while dental specialists took on $-8,5 \pm 5,2$ with specialized patients. A statistically significant relationship $(\mathrm{p}=0.02)$ was found between the dentists' productivity and working with an assistant: dentists, who always work alone, treat fewer patients $(7.9 \pm 3.3)$ than those, who work partially with an assistant $(8,9 \pm 3,7)$. Moreover, dentists, who work in major Lithuanian cities, treat fewer patients $(7.7 \pm 3.6)$ than those, who work in smaller towns $(9 \pm 3,1)$. Also, there was a statistically significant relationship $(\mathrm{p}<0.05)$ between dentists, who work in public hospitals $(10,3 \pm 3,5)$, and dentists, who work in private clinics $(7,6 \pm 3,3)$. Conclusions. Even though the average number of patients treated by general dentists and dental specialists is the same, they differ significantly on various other variables, with the two major ones being the presence of an assistant and the geographical location of the clinic.

Correspondence to: mackeviciute.mon@gmail.com

Gauta 2017-03-05 